Attending to CXCL8, it was associated to consumption of the C4 fraction of complement $(P=0.013)$ and the presence of tortuosities in capillaroscopy $(P=0.02)$ with no other significant findings.

Conclusion: The presence of GDF-15 is associated with diffuse SSc, lung impairment, disease activity and changes in capillaroscopy. In addition, CXCL4 was only associated with skin involvement, while CXCL8 was not related to any organic damage in our patients.

Disclosure of Interests: None declared

DOI: 10.1136/annrheumdis-2020-eular.5019

\section{AB0166 $\quad$ IMMUNOGLOBULIN G DERIVED FROM PATIENTS WITH SYSTEMIC SCLEROSIS IMPRINTS A PRO- INFLAMMATORY AND PRO-FIBROTIC PHENOTYPE IN MONOCYTE-LIKE THP-1 CELLS}

A. Dalmann ${ }^{1}$, S. Murthy ${ }^{2}$, M. Wannick ${ }^{2}$, G. Eleftheriadis ${ }^{2}$, A. Müller ${ }^{1}$, D. Zillikens ${ }^{2}$, H. Busch ${ }^{3}$, C. Sadik ${ }^{2}$, G. Riemekasten ${ }^{1}$. 'University of Luebeck, Department of Rheumatology and Clinical Immunology, Luebeck, Germany; ${ }^{2}$ University of Luebeck, Department of Dermatology, Allergy, and Venereology, Luebeck, Germany; ${ }^{3}$ University of Luebeck, Luebeck Institute for Experimental Dermatology, Luebeck, Germany

Background: Regulatory IgG autoantibodies directed against diverse G protein-coupled receptors (GPCR), i.e. antibodies with agonistic or antagonistic activity are abundant in human serum. The serum titers of autoantibodies targeting angiotensin II receptor $1\left(\mathrm{AT}_{1}\right)$ and endothelin receptor $\mathrm{A}\left(\mathrm{ET}_{\mathrm{A}}\right)$ are specifically altered in autoimmune diseases such as systemic sclerosis (SSc). Disease-promoting mechanisms regulated by anti-AT, and anti-ET $\mathrm{A}_{\mathrm{A}} \lg$ are still elusive, but induction of pro-inflammatory and pro-fibrotic chemokines (CXCL8, CCL18) has been suggested to be one of them.

Objectives: To determine the cytokine and phospho-kinase profiles induced in monocyte-like cells by IgG derived from SSc patients (SSc-lgG) enriched with anti-AT, and anti-ET, antibodies in comparison to IgG derived from healthy donors (IgG-HD)

Methods: A monocyte-like cell line (THP-1) was cultured in vitro and stimulated with $\mathrm{lgG}(1 \mathrm{mg} / \mathrm{ml})$ derived from SSc patients or HD in the presence of various inhibitors/blockers for $24 \mathrm{~h}$. Then, supernatants were analyzed by a human cytokine/chemokine array. Data were analyzed using bio-mathematical tools such as generalized t-test including the robust regression method from R/ Bioconductor package LIMMA. In addition, THP-1 cells were cultured in vitro and stimulated with $\mathrm{IgG}(1 \mathrm{mg} / \mathrm{ml})$ derived from SSc patients or HD for up to 30 minutes. Thereafter, cell lysates were assayed for the kinome employing a human phospho-kinase array. To validate potential effects of transcription factor inhibition, release of CXCL8 and CCL18 into the supernatant was measured by Elisa.

Results: In general, SSc-IgG induced the release of most cytokines by THP-1 cells more pronouncedly than HD-IgG. The bio-mathematical analysis suggested that stimuli, responsible for the shift of the THP-1 cell cytokine profile, are more abundant in SSc-IgG than in HD-IgG. Based upon these findings a gene set enrichment analysis for transcription factors yielded the transcription factors NF-kB, AP-1, and PRDM1 (Blimp-1) as putative major regulatory hubs for the response of THP-1 cells to SSc-IgG. Further, SSc-lgG altered the phosphorylation status of several proteins, indicative of an involvement of MAPK and/or JAK/ STAT pathways. Interestingly, a role for AP-1 was also proposed by the inhibition of CXCL8 and CCL18 release following pretreatment of THP-1 cells with an AP-1 blocker.

Conclusion: Herein, we demonstrate that IgG of SSc patients, enriched with anti-AT, and anti-ET ${ }_{A}$ autoantibodies drives THP-1 cells towards a general pro-inflammatory and pro-fibrotic phenotype, which is reflected by broad changes in the secretome and kinome of these cells. Furthermore, our results highlight AP-1 as critical regulator of gene transcription of CXCL8 and CCL18 in a monocyte-like cell line.

References:

[1] Cabral-Marques O, Marques A, Giil LM, De Vito R, Rademacher J, Günther J, Lange T, Humrich JY, Klapa S, Schinke S, et al. GPCR-specific autoantibody signatures are associated with physiological and pathological immune homeostasis. Nat Commun (2018) 9:5224. doi:10.1038/ s41467-018-07598-9

[2] Günther J, Kill A, Becker MO, Heidecke H, Rademacher J, Siegert E, Radi M, Burmester G-R, Dragun D, Riemekasten G. Angiotensin receptor type 1 and endothelin receptor type $A$ on immune cells mediate migration and the expression of IL- 8 and CCL18 when stimulated by autoantibodies from systemic sclerosis patients. Arthritis Res Ther (2014) 16:R65. doi:10.1186/ ar4503

Disclosure of Interests: Anja Dalmann: None declared, Sripriya Murthy: None declared, Melanie Wannick: None declared, Georgios Eleftheriadis: None declared, Antje Müller: None declared, Detlef Zillikens: None declared, Hauke Busch: None declared, Christian Sadik: None declared, Gabriela Riemekasten Consultant of: Cell Trend $\mathrm{GmbH}$, Janssen, Actelion, Boehringer Ingelheim, Speakers bureau: Actelion, Novartis, Janssen, Roche, GlaxoSmithKline, Boehringer Ingelheim, Pfizer

DOI: 10.1136/annrheumdis-2020-eular.5218

\section{AB0167 1 TOFACITINIB AND NINTEDANIB MODULATE COLLAGEN FORMATION IN DERMAL FIBROBLASTS}

A. S. Siebuhr ${ }^{1}$, M. Karsdal ${ }^{2}$, P. Juhl ${ }^{1}$, A. C. Bay-Jensen ${ }^{1} .{ }^{1}$ Nordic Bioscience, ImmunoScience, Herlev, Denmark; ${ }^{2}$ Nordic Bioscience, $R \& D$, Herlev, Denmark

Background: Dermal fibroblasts are responsible for the excessive extracellular matrix (ECM) formation observed in the skin of systemic sclerosis (SSc) patients and fibroblasts are therefore an obvious target for anti-fibrotic treatments. TGF $\beta$, PDGF and IL- 6 are known to be central cytokines in systemic sclerosis. Nintedanib, a tyrosine-kinase inhibitor approved for treatment of idiopathic pulmonary fibrosis, did not show effect on dermal fibrosis only on pulmonary fibrosis in SSc patients with interstitial lung disease (ILD). Tofacitinib, as Pan JAK inhibitor, has shown to inhibit dermal fibrosis in mouse models and shown positive indications in patients.

Objectives: We investigated the direct effect of Nintedanib and Tofacitinib on ECM production from human dermal fibroblast using translational biomarkers of type I, III and VI collagens and fibronectin.

Methods: Primary healthy human dermal fibroblasts were grown in DMEM media containing $0.4 \%$ fetal calf serum, Ficoll (to produce a crowded environment) and ascorbic acid for up to 17 days. The cells were stimulated with PDGF [3 $\mathrm{nM}$ ] and/or TGF $\beta[1 \mathrm{nM}]$ in combination with Nintedanib [1 $\mathrm{nM}-10 \mu \mathrm{M}$ ] treatment initiated at day 0 or 7 or Tofacitinib [3-100 nM] treatment initiated at culture start together. Media and treatments were changed twice a week. Non-activated cells (w/o) were used as control. Type I, III and $\mathrm{VI}$ collagen formation (PRO-C1, PRO-C3 and PRO-C6, respectively) and fibronectin (FBN-C) were evaluated by validated ELISAs (Nordic Bioscience). Statistical analysis included 1-way and 2-way ANOVA, AUC and Mann-Whitney U-test.

Results: PDGF significantly increased collagen type III and VI formation and collagen type I formation minimally. PDGF did not induce changes in fibronectin levels. TGF $\beta$ increased collagen type I and VI formation but did not induce formation of collagen type III. TGF $\beta$ increased fibronectin levels, where PDGF did not Nintedanib $(\geq 100 \mathrm{nM})$ added either from day 0 or 7 reduced PDGF induced collagen type III and VI formation to the levels of w/o throughout the remainder of the study. In TGF $\beta$ treated fibroblasts, Nintedanib added either from day 0 or 7 reduced collagen type I and VI formation. The fibronectin levels were dose-dependently reduced by Nintedanib. The biomarker levels were at study end at the level of w/o. Nintedanib at a concentration of $1 \mathrm{uM}$ and higher significantly decreased the biomarker levels. Nintedanib $(\geq 100 \mathrm{nM})$ in fibroblasts stimulated with both TGF $\beta$ and PDGF significantly reduced collagen type I, III and VI collagen and fibronectin

A Tofacitinib concentration of $100 \mathrm{nM}$ was toxic to the dermal fibroblasts as the cell viability was minimal at culture end. However, the viability of Tofacitinib (100 nM) in combination with TGF $\beta$ was decreased at study end, but only to half the viability of untreated cells. Tofacitinib dose-dependently decreased the TGF $\beta$ induced type I and III collagen formation and fibronectin in the dermal fibroblasts. Tofacitinib $(100 \mathrm{nM})$ decreased the level of collagen type I and III formation to the level of w/o, where as the level of fibronectin was lowered by $80 \%$ of TGF $\beta$. Tofacitinib as low as $12.5 \mathrm{nM}$ significantly lowered the collagen type I formation and fibronectin (both $\mathrm{p}<0.05$ ) and Tofacitinib of $25 \mathrm{nM}$ decreased collagen type III formation significantly $(p<0.0001)$.

Conclusion: Tofacitinib decreased the formation of the collagens and fibronectin. Nintedanib inhibited ECM production differently in PDGF and TGF $\beta$ induced dermal fibroblast, but in the combination of TGF $\beta$ and PDGF Nintedanib significantly decreased the ongoing fibrosis. In PDGF induced fibrosis, Nintedanib acted as an on-off switch, whereas the inhibition was dose-dependent in TGF $\beta$ induced fibrosis. This cell study indicates that Nintedanib and Tofacitinib inhibits collagen production in dermal fibroblasts. 